\title{
National Health Interview Survey
}

National Cancer Institute

\section{Source}

National Cancer Institute. National Health Interview Survey. NCI Thesaurus. Code

C19752.

Since its inception in 1957, the NHIS has been a continuing nationwide sample survey in which data are collected through personal interviews with household members by U.S. Bureau of the Census interviewers. Data are used to provide national estimates on the incidence of acute conditions, the prevalence of chronic conditions and impairments, the extent of disability, the utilization of health care services (physician visits and hospital episodes), and other health-related topics. All conditions are coded according to the International Classification of Diseases. The survey is periodically redesigned to emphasize data collection on current health issues. (Alcohol Epidemiologic Data Directory, June 2000) 